\title{
Incidence of injuries among male soccer players in the first team of the University of the Free State in the Coca Cola League - 2007/2008 season
}

\author{
Robert Bailey (MB ChB student) ${ }^{1}$ \\ Louisa Erasmus (MB ChB student) ${ }^{1}$ \\ Laetitia Lüttich (MB ChB student) ${ }^{1}$ \\ Nicolas Theron (MB ChB, M Fam Med) ${ }^{2}$ \\ Gina Joubert (BA, MSc) $)^{3}$ \\ ${ }^{1}$ School of Medicine, Faculty of Health Sciences, University of the Free State, Bloemfontein \\ ${ }^{2}$ Private Practitioner, Super Sport Health and Adventure Club, Bloemfontein \\ ${ }^{3}$ Department of Biostatistics, Faculty of Health Sciences, University of the Free State, Bloemfontein
}

\begin{abstract}
Objective. To determine the incidence, nature and severity of injuries among male soccer players in the first soccer team of the University of the Free State (UFS) in the Coca Cola League during the 2007/2008 season. Informed consent was obtained from the players and the study was approved by the Ethics Committee of the Faculty of Health Sciences, UFS.
\end{abstract}

Design. A cohort descriptive study was conducted.

Setting. Twenty-three league matches were attended, during which injury information was recorded on game sheets.

Main outcome measures. The injury type and site, the player game time, and the game period during which the injury occurred were recorded. Follow-up questionnaires were completed for injured players.

Results. In 23 matches played, a total of 15 injuries were sustained by 10 players. The incidence of injuries per 1000 hours game time was 39.5. More injuries occurred at the beginning of the season. Midfield players were most often injured (53\%). Most injuries were minor (class 1 severity), and none exceeded class 3 severity. Most injuries occurred in the first or fourth quarter of the game. Knee and ankle injuries were the most common ( $27 \%$ and

\section{Correspondence:}

Dr Nicolas Theron

Super Sport Health and Adventure Club

PO Box 20151

Willows

Bloemfontein 9320

South Africa

Tel: 27-51-448-1389

Fax: 27-86-529-3148

E-mail: nicolast@iafrica.com
$47 \%$, respectively), consisting mainly of sprains sustained while being tackled.

Conclusion. The most common soccer injuries incurred were to the lower extremity. The relatively low impact nature of the sport resulted in mild to moderate injuries. The incidence of injuries decreased as the season progressed. The results of this study were consistent with those of similar studies reporting the incidence of soccer injuries.

\section{Introduction}

According to the Federation of International Football Associations (FIFA), in 2006 there were approximately 38 million registered soccer players and 226 unregistered occasional players in 207 member countries worldwide. The total number of soccer players has increased by $10 \%$ over a 6 -year period. ${ }^{1}$

Taking the increased popularity of the game and the high expectations of the players into consideration, the number of injuries associated with soccer could be anticipated. ${ }^{2}$ Soccer carries a risk for fractures, sprains, dislocations and other injuries. According to the Centers for Disease Control and Prevention (CDC) ${ }^{3}$ in the USA, soccer injuries in male players accounted for $4.6 \%$ and $3.8 \%$ of non-fatal, unintentional sports- and recreation-related injuries in the 15 -19-year and 20 - 24-year age groups, respectively.

Most soccer injuries involve the lower extremities, are mild to moderate, and are typically sprains or contusions. ${ }^{2,4-8}$ Morgan and Oberlander $^{7}$ reported that $77 \%$ of injuries in major league soccer players in the USA involved the lower extremity, with the knee slightly more often affected than the ankle.

Several studies reported that more injuries occurred during matches than during practice. ${ }^{2,7,8}$ An injury rate of 2.9 per 1000 hours of practice, as opposed to 35.3 per 1000 hours of match play, was noted by Morgan and Oberlander. ${ }^{7}$

In a study of the epidemiology of soccer injuries conducted in Nigeria, ${ }^{2}$ it was found that strikers and defenders were most commonly injured, especially those playing in amateur leagues. The majority of injuries are sustained within the first month of a new season. Kofotolis et al. ${ }^{6}$ reported a $7-8$ times higher rate of ankle 
injuries during the first 2 months compared with the last month of the season. Players with a history of previous injuries were also found to be more prone to sustaining further injuries. ${ }^{6}$

The aims of our study were: $(i)$ to determine the number of injuries incurred per 1000 hours of game time in first team soccer players of the University of the Free State (UFS); and (ii) to describe these injuries with regard to the age of the injured player, his position on the field, previous injuries and how recently these injuries were incurred, the area of the body where the injury was sustained, the mechanism of play, the period of the game when the injury occurred, and the nature and severity of the injury.

\section{Methods}

The terms 'football' (i.e. not American football) and 'soccer' were regarded as synonyms. For the purpose of the study, 'injury' was defined as an injury that occurred during any of the soccer matches observed during the study, resulting in the participant being out of the competition on the day of the injury, or causing the player to miss any practices or matches after the day of the injury. 'Incidence' was defined as the number of new injuries per 1000 match hours. Match time did not include warm-up exercises before the match.

A cohort descriptive study was conducted. The study population consisted of male soccer players who played for the first team of the UFS during the $2007 / 2008$ season. Only players actively participating in the match on the field were included. When any replacement player had to go onto the field, his playing time was included in the study.

No sample selection was performed. Every player fulfilling the inclusion criteria was requested to voluntarily participate in the study. The UFS first team was selected for the study as they participated in the Coca Cola League and played matches on a regular basis.

Twenty-three matches played geographically close to Bloemfontein from August 2007 to January 2008 were covered by the study. The target population included 16 players, of whom 11 were members of the first team and 5 were replacement players (reserves) participating in any of the 23 matches. The estimated game time was 379.5 hours, calculated by 11 players $x 23$ games $x$ 90 minutes per game.

The information of players sustaining an injury during the time period in which the study was conducted, was recorded on specially designed game sheets. Two researchers attended each game and compiled separate game sheets, which were compared after the match to detect if there were any discrepancies.

A follow-up questionnaire containing a data capture sheet was administered in the form of a structured interview. The follow-up interviews were all conducted within 1 month of a player sustaining an injury. The reliability of the information obtained by the game sheets and follow-up interview depended of the accuracy of the recorded information by the researchers.

\begin{tabular}{|ll}
\hline TABLE I. Classification of the severity of injuries & \\
\hline Classification & Amount of time missed \\
1 & Not being able to finish the match owing to injury \\
2 & Missing up to 1 week of play \\
3 & Missing up to 6 weeks of play \\
4 & Missing 6 weeks - 6 months of play \\
5 & Missing $\geq 6$ months of play
\end{tabular}

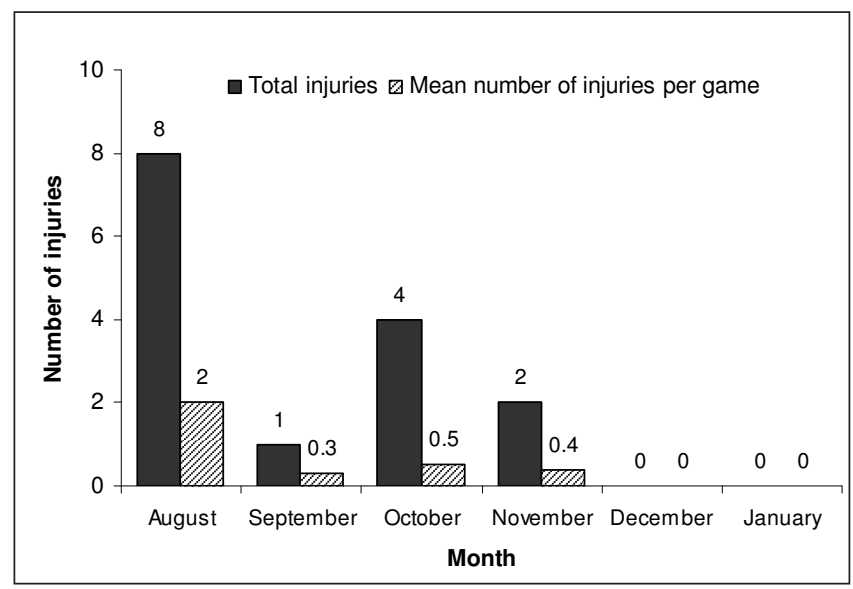

Fig. 1. Distribution of injuries per month throughout the course of the season.

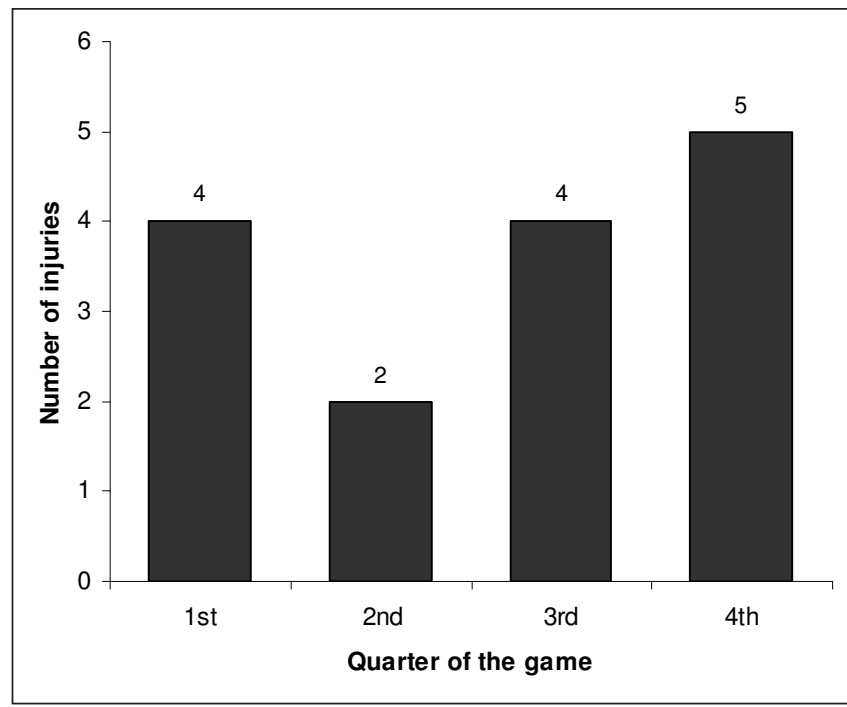

Fig. 2. Distribution of injuries per quarter of the game.

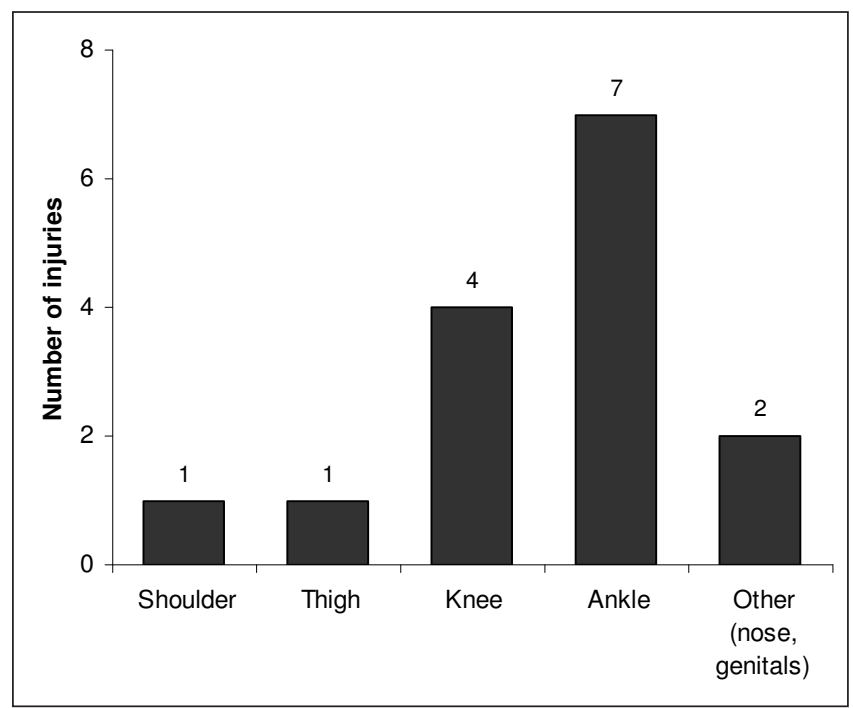

Fig. 3. Body areas affected by injuries sustained.

The severity of the injury was classified according to the amount of game or practice time the player lost as a result of his injury. Table I shows the classification of the severity of injuries, ${ }^{9}$ grade 1 being a minor injury and grade 5 a serious injury. 


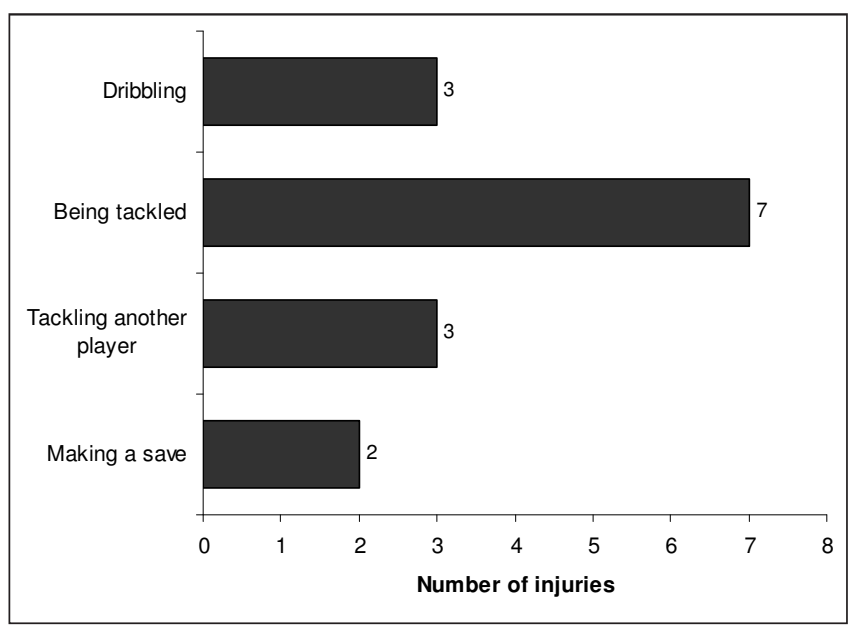

Fig. 4. Mechanism of play carried out when injury occurred.

The Ethics Committee of the Faculty of Health Sciences, UFS, granted approval to perform the research. Permission was also obtained from the Vice-Rector: Student Affairs, UFS, and the coach of the first soccer team. Information regarding the objectives of the study was given to the coach and the players, and each player gave written consent to participate. All data gathered in the study were kept confidential.

In order to test the methodology of the proposed investigation, a pilot study was performed on 2 matches played in August 2007 by the female first soccer team of the UFS after approval had been obtained from the coach, players and Ethics Committee.

Before each game, a complete list of players and their jersey numbers was obtained from the coach for that particular match. All information gathered by the study was treated confidentially. A record of all the players' names and numbers on the back of their jerseys was kept safe and was only accessed by the researchers for the purpose of the study.

\section{Results}

In 23 matches played, a total of 15 injuries were sustained by 10 players. Two players sustained 3 injuries each, 1 player sustained 2 injuries, and 7 players sustained 1 injury each. No injuries occurred in 14 of the matches, 1 injury occurred in 5 matches, 2 injuries in 2 matches, and 2 matches were played in which 3 injuries occurred in each.

The total and mean number of injuries per match occurring per month are shown in Fig. 1. The highest number of injuries occurred during the first month of matches being played, with a steady decline in both the total and mean number of injuries per match each month as the season progressed.

With regard to the position of the injured player on the field, $8(54 \%)$ injuries occurred in midfielders, $3(20 \%)$ each in forward and defence position players and $1(7 \%)$ in the goalkeeper. The median age of the injured players was 22 years (minimum 20 years, maximum 35 years).

Twelve of the 15 injuries ( $80 \%$ ) were classified as grade 1 severity injuries, with the injured player not being able to complete the match. Two injuries (13\%) resulted in the players missing up to 1 week of play (grade 2 severity), while 1 player sustained an injury of grade 3 severity and had to withdraw from play for 6 weeks. No injuries classified as grade 4 and 5 severity were incurred.
The period of the game in which the injuries occurred is shown in Fig. 2. Most injuries occurred in the fourth quarter (5), first quarter (4), and third quarter (4) of the match. During the study, no red card was issued against a player, i.e. there were always 11 players on the field, and no extra time was played. The incidence of injuries per 1000 hours game time was calculated as 39.5 (15 injuries x $100 \div$ 379.5 game hours).

Most injuries were sustained to the ankle (47\%) and the knee (27\%). The body areas affected by the injuries are shown in Fig. 3, while Fig. 4 shows the mechanism of play during which injuries were suffered. Almost half of the injuries (7/15) were incurred when the player was being tackled by an opponent.

Nine of the 15 injuries incurred were sprains, while bruises and dislocations were sustained twice each, and cramping and bleeding once each.

Two of the 15 injured players had a history of previous injuries, both sprains. One player's injury was sustained in the preceding week; he did not seek medical attention. His new injury involved the knee. The other player had sustained a sprain in the preceding month for which he received medical treatment. The new injury sustained was a dislocation of the patella. Both players were being tackled when the new injuries occurred.

\section{Discussion}

More injuries were sustained at the beginning of the season. An increase in the players' fitness levels could explain the decline in the occurrence of injuries towards the end of the season. Kofotolis et al. ${ }^{6}$ reported that the incidence of injuries was significantly higher during the first 2 months of the season compared with the last month.

Players who were involved in more intense contact situations, e.g. midfielders and defenders, were more prone to injury than players in other positions on the field. The correlation between a player's position and the occurrence of injuries is supported by findings reported in the literature, stating that players in contact positions, such as defenders, ${ }^{2,6}$ were more prone to injury.

The observation that most of the injuries were of grade 1 severity and no injury exceeded grade 3 severity, could be ascribed to the relative lack of impact and low-impact nature of the game, i.e. no scrums, rucks (loose scrums) and mauls as in rugby. Azubuike and Okojie $^{2}$ also reported that most soccer injuries were of a moderate nature. On the other hand, compared with injuries sustained from running and racquet sports, soccer injuries were found to be more serious.

Kofotolis et al. ${ }^{6}$ reported that more than $60 \%$ of injuries were observed towards the end of each half of the game. In our study, however, similar rates of injury were observed in the first, third and fourth quarters of the game, where first-quarter injuries could possibly have been attributed to improper warm-up exercises, and fourth quarter injuries to player fatigue.

Because of the nature of the sport, it was not surprising that the two body areas most frequently affected by injury were the ankle $(47 \%)$ and the knee $(27 \%)$. In soccer there is also a low level of contact/impact, which could explain why most of the injuries were sprains $(60 \%)$ and considered as minor injuries. This study confirmed that injuries sustained by soccer players mainly involve the lower extremity, and that less serious injuries occur owing to the low-impact nature of the sport.

The researchers expected to find that players who had previously been injured and had not received medical attention would be more 
prone to injury than those without a history of injury. However, the results showed that this was not necessarily the case, as seen in the 2 injured players who had a history of previous injury.

Ideally, one should have considered all the games played by all the teams in the Coca Cola League, including practice sessions, warm-up exercises and matches. This was, however, not feasible owing to time, and financial and manpower constraints. For future studies of this nature, it is recommended that a larger research team conduct the investigation, and that a larger cohort of participants is included. Furthermore, medical personnel should be available at all matches for sideline evaluation and confirmation of injuries sustained by players.

\section{Acknowledgements}

The authors would like to thank Mr M Mohape, coach of the male first soccer team of the UFS, members of the UFS first soccer team playing in the Coca Cola League, who participated in this study, and Ms Daleen Struwig, medical writer, Faculty of Health Sciences, UFS, for technical and editorial preparation of the manuscript for publication.

\section{References}

1. Federation for International Football Associations (FIFA). FIFA Big Count 2006: 270 million people active in football (http://www.fifa. com $/ \mathrm{mm} / \mathrm{docu}-$ ment/fifafacts/bcoffsurv/bigcount.statspackage_7024.pdf (accessed 17 November 2008)).

2. Azubuike OS, Okojie HO. Epidemiology of soccer injuries in Benin City, Nigeria. Br J Sports Med 2008; 23 October (Epub ahead of print. http://www. ncbi.nlm.nih.gov/pubmed/18927169 (accessed 13 November 2008)).

3. Centers for Disease Control and Prevention (CDC). Nonfatal sports- and recreation-related injuries treated in emergency departments - USA, July 2000 - June 2001. MMWR 2000;51:736-740.

4. Fong DT, Man CY, Yung PS, Cheung SY, Chan KM. Sport-related ankle injuries attending an accident and emergency department. Injury 2008;39:1222-1227.

5. Hägglund $M$, Waldén $M$, Ekstrand J. Injuries among male and female elite football players. Scand J Med Sci Sports 2008; 13 October (Epub ahead of print. http://www.ncbi.nlm.nih.gov/pubmed/18980604 (accessed 13 November 2008))

6. Kofotolis ND, Kellis E, Vlachopoulos SP. Ankle sprain injuries and risk factors in amateur soccer players during a 2-year period. Am J Sports Med 2007;35:458-466.

7. Morgan BE, Oberlander MA. An examination of injuries in Major Soccer League. The inaugural season. Am J Sports Med 2001;29:426-430.

8. Yard EE, Schroeder MJ, Fields SK, Collins CL, Comstock RD. The epidemiology of United States high school soccer injuries, 2005-2007. Am J Sports Med 2008;36:1930-1937.

9. Van Mechelen W. The severity of sports injuries. Sports Med 1997;24:176180. 